\title{
Recent Trends in Analytical Techniques for the Development of Pharmaceutical Drugs
}

\author{
Ravali $\mathbf{R}^{1 *}$, Phaneendra $\mathbf{M}^{2}$, Bhanu Jyothi $\mathrm{K}^{3}$, Ramya Santhoshi $\mathrm{L}^{4}$ and Sushma $\mathrm{K}^{5}$
}

${ }^{1}$ Department of Biotechnology, Periyar University, Tamilnadu, India

${ }^{2}$ Department of Biotechnology, GITAM University, Visakhapatnam, India

${ }^{3}$ Department of Organic Chemistry, Andhra University, Visakhapatnam, India

${ }^{4}$ Department of Microbiology, Andhra University, Visakhapatnam, India

${ }^{5}$ Department of Biochemistry, Andhra University, Visakhapatnam, India

\begin{abstract}
Growing interest in the evolution of Pharmaceutical Drugs had made to bring certain analytical techniques into limelight. Many such techniques are used to extract, purify and characterize (structurally and molecularly), newly produced vital drugs. This review gives information regarding emerging trends in using various analytical techniques like HPLC, HPTLC, LC-MS/MS, etc.In development of newly producing drugs. The proposed methods were statistically equivalent and showed satisfactory results.
\end{abstract}

Keywords: HPLC (High Performance Liquid Chromatography); HPTLC (High Performance Thin Layer Liquid Chromatography); LCMS/MS (Liquid Chromatography- Mass Spectroscopy)

\section{Introduction}

Drug Development projects can generate hundreds of thousands of compounds that scientist may analyse to characterize structures and identify the impurities. Once they have identified drug target and have run bioassay to understand better how it functions, they can focus their efforts on finding small organic molecules that alter the target functions. To analyse these small entities as well as larger molecules, life scientists increasing relay on methods like HPLC, HPTLC, LC-MS. Liquid chromatography-mass spectrometry (LC-MS) is an analytical technique that couples high resolution chromatographic separation with sensitive and specific mass spectrometric detection. This includes high performance liquid chromatography (HPLC)-MS. It is probably the most powerful technique for pharmaceutical analysis. The major applications of LC-MS in pharmaceutical analysis have been in drug metabolism studies, the analysis and identification of impurities and degradation products in pharmaceuticals and the isolation and characterization of potential drug substances from natural synthetic sources.

\section{HPLC}

High Performance Liquid Chromatography (HPLC) is one mode of chromatography, one of the most used analytical techniques. Chromatographic process can be defined as separation technique involving mass-transfer between stationary and mobile phase. HPLC utilises a liquid mobile phase to separate the components of a mixture. The stationary phase can be a liquid or a solid phase. These components are first dissolved in a solvent, and then forced to flow through a chromatographic column under a high pressure. In the column, the mixture separates into its components. The amount of resolution is important, and is dependent upon the extent of interaction between the solute components and the stationary phase. The stationary phase is defined as the immobile packing material in the column. The interaction of the solute with mobile and stationary phases can be manipulated through different choices of both solvents and stationary phases. Thyagarajapuram et al. [1] has developed an LCmethod for the determination of amiodarone hydrochloride in tablet and injectable formulations [2]. An HPLC method was also developed and validated for the determination of amiodarone hydrochloride and its related compounds in amiodarone hydrochloride injections by Christopherson et al. [3]. As a result, HPLC acquires a high degree of versatility not found in other chromatographic systems and it has the ability to easily separate a wide variety of chemical mixtures. High performance liquid chromatography is basically a highly improved form of column chromatography. A simple, precise, accurate, and stability-indicating liquid chromatographic method was validated for the determination of amiodarone hydrochloride impurities (amiodarone impurity D and impurity E) as well as for the determination of amiodarone hydrochloride in tablet formulations. Liquid chromatography with a UV detector at a wavelength of 240 nm using a $\mathrm{C}_{18}$ column was employed in this study. Isocratic elution was employed using a mixture of buffer solution $\mathrm{pH}$ 5.0, methanol, and acetonitrile (30:30:40, v/v/v). This method was validated for the determination of amiodarone hydrochloride in accordance with USP requirements for assay determination, which include accuracy, precision, selectivity, linearity and range [4]. High performance liquid chromatographic (HPLC) separation on a BDS Hypersil $\mathrm{C}_{18}$ column using disodium hydrogen phosphate buffer $(0.02 \mathrm{M})$ : Methanol (25: $75, \mathrm{v} / \mathrm{v}) \mathrm{pH}$ adjusted to 7 with ortho-phosphoric acid as the mobile phase. The proposed methods were validated as per ICH guidelines and successfully applied for the determination of investigated drugs in tablets [5]. High performance liquid chromatography [6] and LC/ ESI-MS/MS [7] methods have been reported for the estimation of gatifloxacin in dosage forms and from human plasma. The aim of this study was to develop and validate for determination of piroxicam in human plasma by new rapid HPLC method and to compare the relative bioavailability of two branded formulations of piroxicam in healthy Korean volunteers [8]. Bioanalytical, HPLC and stability indicating

*Corresponding author: Ravali R, Department of Biotechnology, Periyar University, Tamilnadu, India, E-mail: ravali.ragula@yahoo.com

Received March 30, 2011; Accepted April 15, 2011; Published April 17, 2011

Citation: Ravali R, Phaneendra M, Bhanu Jyothi K, Ramya Santhoshi L, Sushma K (2011) Recent Trends in Analytical Techniques for the Development of Pharmaceutical Drugs. J Bioanal Biomed S11. doi:10.4172/1948-593X.S11-002

Copyright: (C) 2011 Ravali R, et al. This is an open-access article distributed under the terms of the Creative Commons Attribution License, which permits unrestricted use, distribution, and reproduction in any medium, provided the original author and source are credited. 
HPLC methods are reported for its individual determination and in combination with other drugs [9-12].This work is concerned with the research and development of methodology for analysis of complex mixtures such as pharmaceutical or food samples, which contain many analytes

Automated development in HPTLC: High performance thin layer chromatography (HPTLC) is an enhanced form of thin layer chromatography (TLC). A number of enhancements can be made to the basic method of thin layer chromatography to automate the different steps, to increase the resolution achieved and to allow more accurate quantitative measurements. Automation is useful to overcome the uncertainty in droplet size and position when the sample is applied to the TLC plate by hand. Nowadays, HPTLC has become a routine analytical technique due to its advantages of reliability in quantitation of analytes at micro and even in nanogram levels and cost effectiveness [13]. Recently an HPLC and HPTLC method has been reported for simultaneous estimation of levocetirizine dihydrochloride and Montelukast sodium in pharmaceutical dosage forms which are either tedious or expensive methods $[14,15]$.

This chromatographic process relies on the property of biologically active substances to form stable, specific, and reversible complexes. The formation of these complexes involves the participation of common molecular forces such as the Van der Waals interaction, electrostatic interaction, dipole-dipole interaction, hydrophobic interaction, and the hydrogen bond. An efficient, biospecific bond is formed by a simultaneous and concerted action of several of these forces in the complementary binding sites.

Development of RP-HPLC: A simple and rapid method for the determination of ATP, ADP, AMP, $\mathrm{NADP}^{+}, \mathrm{NAD}^{+}, \mathrm{NADPH}$, and $\mathrm{NADH}$ in human erythrocytes. Analysis is performed by reversephase high-performance liquid chromatography on a 5- $\mu \mathrm{m}$ Supelcosil LC-18 column and uv detection. Reversed phase HPLC (RP-HPLC or RPC) has a non-polar stationary phase and an aqueous, moderately polar mobile phase. A simple, fast and precise reversed phase high performance liquid chromatographic method has been developed for the simultaneous determination of Camylofin dihydrochloride and Diclofenac Potassium using Methylparaben as an internal standard. Efficient chromatographic separation was achieved on Inertsil $\mathrm{C}_{1}$ column $(250 \mathrm{~mm} \times 4.6 \mathrm{~mm}, 5 \mu \mathrm{m})$ as stationary phase with a mobile phase comprising of $0.05 \mathrm{M} \mathrm{KH}_{2} \mathrm{PO}_{4}$ in water : Methanol $(35: 65, \mathrm{v} / \mathrm{v})$ at a flow rate of $1.5 \mathrm{~mL} \mathrm{~min}{ }^{-1}$, column temperature of $27^{\circ} \mathrm{C}$ and UV detection at $220 \mathrm{~nm}$. The proposed method was validated for linearity, accuracy, precision, sensitivity, robustness and solution stability. Linearity, accuracy and precision were found to be acceptable over the ranges of $250-750 \mu \mathrm{g} \mathrm{mL} \mathrm{m}^{-1}$ for both camylofin dihydrochloride and diclofenac potassium. The test solution was found to be stable for 48 hours. It can be conveniently adopted for routine quality control analysis [16]. The literature revealed no method was available for simultaneous determination of this drug in such pharmaceutical preparation by HPLC [17-21]. A new simple, rapid and precise reverse phase high pressure liquid chromatography (RP-HPLC) method was developed for the simultaneous estimation of amoxicillin trihydrate and bromhexine hydrochloride from oily suspension. An ODS C $C_{18}(250$ $\mathrm{X} 4.5 \mathrm{~mm}$ ID), $5 \mu$ particle size with mobile phase methanol and glacial acetic acid (50:50 v/v) were used [22]. An improved derivatives RPHPLC method with PDA detection has been developed and validated for the simultaneous estimation of tranexamic acid and mefenamic acid in combined tablet dosage form [23]. A rapid, sensitive and specific RP-HPLC method involving UV detection was developed and validated for determination and quantification of Moxifloxacin $\mathrm{HCl}$ in tablet dosage form. The method does require only $10 \mathrm{~min}$ as run time for analysis which proves the adoptability of the method for the routine quality control of the drug [24]. Two chromatographic methods have been described for the simultaneous determination of levocetirizine dihydrochloride and Montelukast sodium in tablets. The first method was a high performance thin layer chromatographic (HPTLC) separation followed by densitometric measurements on normal phase silica gel $60 \mathrm{~F}_{254}$

Simultaneous analysis: In the present paper we report our work on development and validation of TLC densitometric method for simultaneous quantification of Bergenin, (+)-Catechin, Gallicin and Gallic acid, and quantification of B-Sitosterol using HPTLC. Bioautography is a microbial detection method hyphenated with planar chromatography techniques. It is based mainly on antimicrobial or antifungal properties of analyzed substances. Developed method permitted simultaneous quantification of Bergenin, (+)-Catechin, Gallicin and Gallic acid, and showed good resolution and separation from other constituents of extract and was found to be simple, precise, specific, sensitive and accurate. It can be adopted for routine quality control of herbal material and formulations containing Bergenia ciliata. [25]. A simple, fast and precise reversed phase high performance liquid chromatographic method has been developed for the simultaneous determination of Camylofin dihydrochloride and Diclofenac Potassium using Methylparaben as an internal standard [26].

A rapid and accurate liquid chromatographic method has been developed for the simultaneous determination of gatifloxacin (GFC) and ambroxol hydrochloride (AMB) in a tablet formulation. The method was validated for accuracy, precision and recovery studies. Statistical analysis proved the method was precise, reproducible, selective, specific, and accurate for analysis of GFC and AMB. The wide linearity range, sensitivity, accuracy, short retention time, and simple mobile phase imply the method is suitable for routine quality control of formulation products [27] recovery values for Atorvastatin, Ezetimibe and Fenofibrate ranged from $99.7-101.1 \%, 99.8-101.3 \%$ and $99.7-$ $101.7 \%$, respectively. The relative standard deviation for six replicates is always less than $2 \%$. This HPLC method is successfully applied to the simultaneous quantitative analysis of the drugs. A reverse phase high pressure liquid chromatography (RP-HPLC) method was developed for the simultaneous estimation of amoxicillin trihydrate and bromhexine hydrochloride from oily suspension. Efficient chromatographic separation was achieved on Inertsil $\mathrm{C}_{18}$ column $(250 \mathrm{~mm} \times 4.6 \mathrm{~mm}, 5 \mu \mathrm{m})$ as stationary phase with a mobile phase comprising of $0.05 \mathrm{M} \mathrm{KH}_{2} \mathrm{PO}_{4}$ in water: Methanol $(35: 65, \mathrm{v} / \mathrm{v})$ at a flow rate of $1.5 \mathrm{~mL} \mathrm{~min}^{-1}$, column temperature of $27^{\circ} \mathrm{C}$ and UV detection at $220 \mathrm{~nm}$. The retention time of Methylparaben, Camylofin dihydrochloride and Diclofenac potassium were $3.60 \mathrm{~min}, 4.85 \mathrm{~min}$ and $13.10 \mathrm{~min}$ respectively [28].The liquid chromatographic method has been developed for the simultaneous determination of gatifloxacin (GFC) and ambroxol hydrochloride $(\mathrm{AMB})$ in a tablet formulation. Chromatographic separation of the two drugs was achieved on a Phenomenex column $(200 \mathrm{~mm} \times 4.6 \mathrm{~mm}$, $5 \mu \mathrm{m})$ [29]. Simultaneous determination of Atorvastatin, Ezetimibe and Fenofibrate in their ternary mixture of commercial pharmaceutical preparations. This method, reported first time for a ternary mixture, uses a Kromasil C18, $250 \times 4.6 \mathrm{~mm}, 5 \mu \mathrm{m}$ analytical column [30] An HPLC method for the simultaneous quantitative determination of betamethasone and clotrimazole in cream formulation has been developed [31]. 


\section{LC-MS Method}

LC/MS methods are applicable to a wide range of compounds of pharmaceutical interest, sensitivity, selectivity, speed of analysis, and cost effectiveness.These analytical features have continually improved, resulting in easier to use and more reliable instruments. These improvements were timely and coincided with the aforementioned developments in the pharmaceutical industry. Analytic technique by which chemical substances are identified by sorting gaseous ions by mass using electric and magnetic fields. A mass spectrometer uses electrical means to detect the sorted ions, while a mass spectrograph uses photographic or other non electrical means either device is a mass spectroscope. The process is widely used to measure masses and relative abundances of different isotopes, to analyze products of a separation by liquid or gas chromatography, to test vacuum integrity in high-vacuum equipment, and to measure the geological age of minerals.

\section{Applications of this Method in clinical samples}

- LC-MS/MS method used for Simultaneous Quantification of Seven Anti-HIV Medicines in Plasma of HIV-infected Patients [32].

- A liquid chromatography-tandem mass spectrometry (LC-MSMS) method for the screening and confirmation of mescaline in human urine samples and to apply this method to routine testing in patient samples.

- A highly sensitive, rapid assay method has been developed and validated for the simultaneous estimation of tolmetin (TMT) and MED5 in human plasma with liquid chromatography coupled to tandem mass spectrometry with electrospray ionization in the positive-ion mode. A simple solid-phase extraction process was used to extract TMT and MED5 along with mycophenolic acid (internal standard, IS) from human plasma.

- LC-MS/MS method for determination of the Paclitaxel in human plasma was developed and validated [33].

- Quantitative Estimation of Amlodipine Desolate, Olmesartan Medoxomil and Hydrochlorthiazide in Tablet Dosage Form [34].

- Epigenetic regulators have quickly become one of the most widely studied therapeutic agents for a vast array of diseases, making histone deacetylase inhibitors (HDIs) and DNA methyltransferase (DNMT) inhibitors commonly used molecules in pre-clinical and clinical anti-cancer studies [35].

- A sensitive HPLC method was established and evaluated for determining the concentrations of paeonol in mice plasma. $180 \mathrm{KM}$ male mice of $22 \sim 28 \mathrm{~g}$ body weight were divided into three groups randomly and purified paeonol, Moutan Cortex decoction and Rhubarbmoutan decoction were orally administered at equivalent doses of $10 \mathrm{mg} \cdot \mathrm{kg}^{-1}$ paeonol [36].

- To investigate the bioequivalence of the final tablet formulation of eslicarbazepine acetate (ESL) and the tablet formulation used in pivotal clinical studies [37].

- The bioavailability of nimesulide was $89.42 \%$ after i.m administration. These pharmacokinetic data suggests that nimesulide given intramuscularly may be useful in the treatment of inflammatory disease conditions in bovines [38].
- LC-MS/MS assay was developed for the determination of bupropion and its metabolite hydroxybupropion in human plasma using lidocaine. Based on the $90 \%$ confidence interval of the individual ratios it was concluded that the test formulation is bioequivalent to the reference formulation with respect to the rate and extent of absorption of both bupropion and hydroxybupropion and that food intake before the drug administration had no effect in the relative pharmacokinetic parameters. However, the hyperlipemic meal significantly increased the bupropion absorption [39].

- The most important feature in transbuccal drug delivery is the low drug passage through the buccal mucosa [40]

- The concept of sustained delivery of rapamycin using ReGel as a promising strategy to inhibit SMC proliferation for the prevention of hemodialysis arteriovenous graft stenosis [41].

- Simultaneous determination of multiple components by the flow injection technique (MC FIA) of various configurations with a single detector (single or multichannel), or with several detectors in series or in parallel.

- A simple, rapid and precise reversed-phase liquid chromatographic method is developed for simultaneous determination of Atorvastatin, Ezetimibe and Fenofibrate in their ternary mixture of commercial pharmaceutical preparations. This HPLC method is successfully applied to the simultaneous quantitative analysis of the drugs in tablets [42].

- In the present study, comprehensive stress testing of tenatoprazole was carried out according to ICH guide-line Q1A (R2). Tenatoprazole was subjected to stress conditions of hydrolysis, oxidation, photolysis and neutral decomposition. Extensive degradation was found to occur in acidic, neutral and oxidative conditions. Mild degradation was observed in basic conditions. The drug is relatively stable in the solid-state.

- Tablet formulation of eslicarbazepine acetate (ESL) and the tablet formulation used in pivotal clinical studies.

- Application of UV-Spectroscopy and First Order Derivative Method for Determination of Tamsulosin Hydrochloride in Bulk and Tablets [43].

- DNA-based tetravalent dengue vaccine can induce balanced neutralizing antibody responses against all four types of dengue virus (DENV1-4), using naïve mice. The dengue tetravalent DNA vaccine could provide balanced induction of dengue antibody responses even in mice preimmunized with any of the three flaviviruses, at least after the second vaccination [44].

- V-5 Immunitor (V5) has been evaluated in patients with chronic hepatitis $\mathrm{C}$ with concomitant HIV and Mycobacterium Tuberculosis infections [45].

- The purpose of this study was to develop a single-laboratory validated (SLV) method using high-performance liquid chromatography with different detectors. The method does not require any sample cleanup/preconcentration steps except centrifugation and filtration [46].

- Some liquid chromatographic (LC) methods for determination of milnacipran combined with other antidepressants in human plasma have already been published [47-51]. A micellar 
electrokinetic capillary chromatographic method was developed for separation and determination of antidepressants and their metabolites in biological fluids [52] and LC enantioseparation of milnacipran was investigated on different cellulose-based chiral stationary phases [53].

\section{Automated injection technique}

Automation is a critical demand in modern pharmaceutical analysis and quality control, since strict legislation regarding Good Laboratory (GLP) and Manufacturing Practice (GMP) require extensive analyses of huge amounts of samples during all stages of the manufacturing process of a pharmaceutical formulation. An automated flow injection determination of some phenothiazine derivatives, based on their oxidation with iron (III) in a strongly acidic medium. A flow injection spectrophotometric procedure is proposed for determining adrenaline in pharmaceutical formulations. A simple, rapid and precise reversedphase liquid chromatographic method is developed for simultaneous determination of Atorvastatin, Ezetimibe and Fenofibrate in their ternary mixture of commercial pharmaceutical preparations. Extensive analyses of huge amounts of samples during all stages of the Manufacturing process of a pharmaceutical formulation [54]. Automation is a critical demand in modern pharmaceutical analysis and quality control, since strict legislation regarding Good Laboratory (GLP) and Manufacturing Practice (GMP) require extensive analyses of huge amounts of samples during all stages of the manufacturing process of a pharmaceutical formulation.

Future trends in automated injections: The auto-injectors are having rapid growth in the fields of Pharmacy. This article discusses the benefits driving this growth, the current state of the technology. An auto-injector may be described as a device which completely or partially replaces the activities involved in parenteral drug delivery from a standard syringe. It is likely that there will be continued growth in next few years in the variety of auto-injectors, with competition to meet requirements spurring innovation in new therapy areas. The deserved success is underpinned by the principles of quality, safety and efficacy and will certainly continue to be an important part of patients' lives, particularly those who enjoy the benefits of taking an active role in their treatment.

\section{Bioequalence and bioavailability studies of pharmacokinetics}

Bioequivalence approaches are commonly based on the two one-sided tests principle. Average bioequivalence is the special case of population bioequivalence, where the entire distributions of bioavailabilities are considered. Statistical approaches for population bioequivalence are suggested. Population bioequivalence is an improvement over average bioequivalence, because average bioequivalence does not consider the variability of the formulations [55]. Various experiments have been performed to improve the bioavailability of this drug such as binding with polymers [56].

Two pharmaceutical products are bioequivalent if they are pharmaceutically equivalent and their bioavailabilities (rate and extent of availability) after administration in the same molar dose are similar to such a degree that their effects, with respect to both efficacy and safety, can be expected to be essentially the same. Bioequivalence approaches are commonly based on the two one-sided tests principle. Average bioequivalence is the special case of population bioequivalence, where the entire distributions of bioavailabilities are considered. Various experiments have been performed to improve the bioavailability of this drug such as binding with polymers [57], co administration with Cyclosporine A [58] or administration by liposome's [59]. Pharmaceutical equivalence implies the same amount of the same active substances, in the same dosage form, for the same route of administration and meeting the same or comparable standards. There is no clinically significant difference between the two treatments for all the safety parameters [60].A sensitive HPLC method was established and evaluated for determining the concentrations of paeonol in mice plasma. All the results indicate those dispositions in mice were affected by other components in Chinese herbs and in recipe. Plasma samples were analyzed for PX by a validated UV-HPLC method [44]. The treatment of Inflammatory Bowel Diseases (IBDs) requires a relative high therapeutic daily dose of mesalazine and thus, the drug formulation need to be well tolerated and safe. These pharmacokinetic data suggests that nimesulide given intramuscularly may be useful in the treatment of inflammatory disease conditions in bovine [62]. Prolonged pharmacokinetic sampling is a challenge for successful conduction of the bioequivalence studies for drugs having long elimination half-lives. The regulatory authorities have recommended an alternative to consider the partial AUC $\left(\mathrm{AUC}_{0-72}\right)$ for studying bioequivalence [45]. Enteric coated $400 \mathrm{mg}$ tablets administered in the same time were measured with a validated high performance liquid chromatography-tandem mass spectrometry method. $\mathrm{C}_{\max }$ $\mathrm{t}_{\max }$ and AUC (Area under Curve) values were considered as primary variables and the drug safety was the secondary one. Bioequivalence of the final tablet formulation and the tablet formulation used in the pivotal clinical trials of ESL has been demonstrated .The aim of this study was to develop and validate for determination of piroxicam in human plasma by new rapid HPLC method and to compare the relative bioavailability of two branded formulations of piroxicam in healthy Koreans. Comparative Bioavailability and Pharmacodynamic Aspects of Cyclobenzaprine and Caffeine in Healthy Subjects and the Effect on Drowsiness Intensity. A specific, fast and sensitive LC-MS/MS assay was developed for the determination of cyclobenzaprine in human plasma using imipramine as the internal standard [15]. LC-MS/MS assay was applied to a comparative pharmacokinetic study, in which seventy eight volunteers ( 39 men and 39 female) aged between 18 and 50 years received a single oral dose of $150 \mathrm{mg}$ of reference and test bupropion formulation, in an open, two-period, balanced randomized, crossover protocol. Group 1 received the medication without any additional meal. Group two received a hyperlipemic meal $30 \mathrm{~min}$ before the medication. The drug administration had no effect in the relative pharmacokinetic parameters. However, the hyperlipemic meal significantly increased the bupropion absorption included 26 healthy adult male and female subjects under fasting conditions. In each of the two study periods (separated by a washout of one week) single dose of test or reference drug was administered. Blood samples were taken up to $72 \mathrm{~h}$ post dose, the plasma was separated and the concentrations of naproxen were determined by HPLC-UV method [63]. AUC Method on Drug Bioequivalence in Humans supports the bioequivalence of drugs [46]. A biocompatible and biodegradable natural polymer is used to increase drug bioavailability, as well as prolonging release. The aim of this study was to investigate the feasibility of enhancement of oral bioavailability of PX using $\mathrm{CH}$. Bioavailability and Interaction Potential of Atorvastatin and Losartan on Co-administration in Healthy Human Subjects. Based on this study, it can be concluded that the two naproxen sodium tablets (test and drug reference drug) were bioequivalent in term of the rate and extent of absorption.

\section{Pharmaceutical nanotechnology}

The emerging pharmaceutical nanotechnology industry is better off 


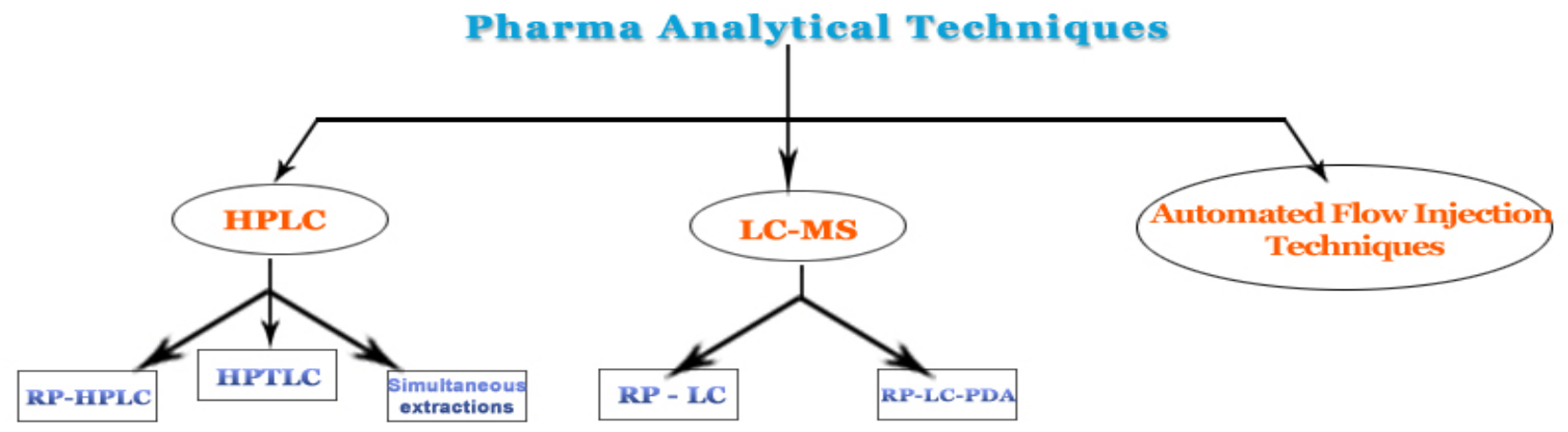

Figure 1: Pharma Analytical Techniques Flow Chart.

being proactive in its response to these emerging concerns by collecting its own product-safety data and using them to design new safe products and provide information to regulatory bodies. The aim of the present investigation was to improve solubility and dissolution of the lipophilic drug aceclofenac using three nanocarriers namely nanoemulsion, solid lipid nanosuspension and polymeric nanosuspension. The solubility of aceclofenac in distilled water and different nanocarriers was determined using the UV spectrophotometer method at the wavelength of $274 \mathrm{~nm}$. The solubility and dissolution were highly significant in nanoemulsion as compared to lipid and polymeric nanosuspension $(\mathrm{P}<0.01)$. Dissolution profile of aceclofenac in lipid and polymeric nanosuspension was significant as compared to pure aceclofenac suspension $(\mathrm{P}<0.05)$. These results indicated that nanoemulsion is a promising nanocarriers as compared to lipid and polymeric nanosuspension for solubility and dissolution enhancement of aceclofenac (Figure 1).

Future trends in drug development: Pharmaceutical analysis referred to the chemical analysis of drug molecules. However, over the years, modern pharmaceutical analysis has evolved beyond this to encompass combination techniques, high-throughput technologies, chemo metrics, micro dosing studies, miniaturization and nanotechnology. These analytical advances are now being employed in all stages of drug discovery and the focus of this review will be on how these technologies are being employed within this process. With new, improved and evolving technologies, as well as new applications for existing technology, the search for new drugs for the prevention and treatment of human diseases continues. Automated combinatorial chemistry can now synthesize a near-infinite number of compounds. The problem is narrowing down the possibilities to a reasonable subset to synthesize and screen. Metabolic determinations are an integral part of every drug-discovery and drug-development. Recent emphasis has been to increase sample throughput while, at the same time, increase information content within assays. To this end, screening for potential drug-drug interactions, overall metabolic stability and metabolite profiles are used early in discovery to select compounds for development. It is a novel liquid chromatography and mass spectrometry as the preferred analytical tool, and potential solutions to maximize output.

\section{Conclusion}

In short, the goal over the next 10 years will be to turn the existing 70 percent compound failure rate into a 70 percent success rate. Technologies are available to challenge this paradigm in the areas of focused compound synthesis, storage and handling of compounds and information-rich assays, however, these will continue to present both excitement and challenge for those engaged in the discovery of new drugs for some time to come. The results demonstrated that this analytical Technique are accurate, precise, specific, linear, reliable, sensitive, and fast [64].

\section{References}

1. Lacroix PM, Curran NM, Wing-Wah SY, Gorecki DKJ, Thibault P, et al. (1994) Liquid chromatographic determination of amiodarone hydrochloride and related compounds in raw materials and tablets. J AOAC Int 77: 1447-1453.

2. Thyagarajapuram N, Alexander KS (2003) A simplified method for the estimation of amiodarone hydrochloride by reverse-phase high performance liquid chromatography. J Liq Chrom \& Rel Technol 26: 1315-1326.

3. Christopherson MJ, Yoder KJ, Miller RB (2004) Validation of a stabilityindicating HPLC method for the determination of amiodarone $\mathrm{HCl}$ and its related substances in amiodarone $\mathrm{HCl}$ injection. J Liq Chrom \& Rel Technol 27: 95111.

4. Al-Rimawi F (2010) Validation of an HPLC-UV Method for the Determination of Amiodarone Impurities in Tablet Formulaions. Pharm Anal Acta 1:105.

5. Rathore AS, Sathiyanarayanan L, Mahadik KR (2010) Development of Validated HPLC and HPTLC Methods for Simultaneous Determination of Levocetirizine Dihydrochloride and Montelukast Sodium in Bulk Drug and Pharmaceutical Dosage Form. Pharm Anal Acta 1:106.

6. Liang H, Kays MB, Sowinski KM (2002) Separation of levofloaxacin ciprofloxacin, gatifloxacin, moxifloxacin, trovafloxacin and cinoxacin by HPLC: application to levofloxacin determination in human plasma. J Chromatogr B Analyt Technol Biomed Life Sci 772: 53-63.

7. Sistla R, Tata VS, Kashyap YV, Chandrasekar D, Diwan PV (2005) Development and validation of a reversed-phase HPLC method for the determination of ezetimibe in pharmaceutical dosage forms. J Pharm Biomed Anal 39: 517-522.

8. Sonawane SS, Shirkhedkar AA, Fursule RA, Surana SJ (2006) Application of UV-Spectrophotometry and RP-HPLC for Simultaneous Determination of Atorvastatin Calcium and Ezetimibe in Pharmaceutical Dosage Form. Eurasian Journal of Analytical Chemistry 1: 31-41.

9. Kumar DA, Sujan DP, Vijayasree V, E Rao JVLNS (2009) Simultaneous Determination of Simvastatin and Ezetimibe in Tablets by HPLC. Journal of Chemistry 6: 541-544.

10. Singh S, Singh B, Bahuguna R, Wadhwa L, Saxena R (2006) Stress degradation studies on ezetimibe and development of a validated stability-indicating HPLC assay. J Pharm Biomed Anal 41: 1037-1040a.

11. Doshi AS, Kachhadia PK, Joshi HS (2008) Validation of a Stability-Indicating LC Method for Assay of Ezetimibe in Tablets and for Determination of Content Uniformity. Chromatographia 67: 137-142.

12. Oswald S, Scheuch E, Cascorbid I, Siegmund W (2006) J Chromatogr B 830 143-150a. 
Citation: Ravali R, Phaneendra M, Bhanu Jyothi K, Ramya Santhoshi L, Sushma K (2011) Recent Trends in Analytical Techniques for the Development of Pharmaceutical Drugs. J Bioanal Biomed S11. doi:10.4172/1948-593X.S11-002

Page 6 of 7

13. Shuijun L, Gangyi L, Jingying J, Xiaochuan L, Chen Y (2006) J Pharm Biomed Anal 40: 987-992.

14. Vishwanathan K, Bartlett MG, Steward JT (2001) Determination of gatifloxian in human plasma by liquid chromatography/electrospray tandem mass spectroscopy. Rapid Commun Mass Spectrom 15: 915-919.

15. Song HH, Choi KS, Kim CW, Kwon YE (2009) Pharmacokinetic Profiles of Two Branded Formulations of Piroxicam 20mg in Healthy Korean Volunteers by a Rapid Isocratic HPLC Method. J Bioequiv Availab 1: 074-081.

16. Ni Y, Liu Y, Kokot S (2011) Two-dimensional fingerprinting approach for comparison of complex substances analysed by HPLC-UV and fluorescence detection. Analyst. 136:550-559.

17. Elbarbry FA, Mabrouk MM, El-Dway MA (2007) Determination of the analgesic components of Spasmomigraine tablet by liquid chromatography with ultraviolet detection. J AOAC Int 90: 94-101a.

18. Hinz B, Chevts J, Renner B, Wuttke H, Rau T, et al. (2007) Bioavailability of diclofenac potassium at low doses. Br J Clin Pharmacol 59: 80-84.

19. G Subramanian, P Musmade, S Agarwal, N Udupa (2004) Simultaneous RP HPLC estimation of tinidazole, diclofenac potassium and paracetamol in tablets. Indian journal of pharmaceutical sciences 66: 694-696a.

20. Barde PS, Desai AY, Roy MNS, Vaidya VV (2008) Simultaneous RP HPLC determination of Camylofin dihydrochloride in Pharmaceutical preparation. TSI Journal 7(10)a.

21. Singh RR, Rathnam MV, Vegesna R (2008) Simultaneous RP HPLC determination of Camylofin dihydrochloride and Paracetamol in Pharmaceutical preparations.TSI Journal 7(11).

22. Sethi PD (1992) Identification of Drugs in Pharmaceutical Formulations by Thin Layer Chromatography. CBS Publishers, New Delhi.

23. Ashok kumar S, Senthil Raja M, Perumal P (2009) RP-HPLC Method Development and Validation for Simultaneous Estimation of Montelukast Sodium and levocetirizine Dihydrochloride. International journal of pharmaceutical research 1: 8-12.

24. Smita Sharma MC, Sharma DV, Kohlib AD, Sharma C (2010) Development and validation of tlc-densitometry method for simultaneous quantifi cation of montelukast sodium and levocetirizine dihydrochloride pharmaceutical solid dosage form. Der Pharmacia Lettre 2: 489-494.

25. Rathnam MV, Singh RR (2010) Simultaneous RP HPLC Determination of Camylofin Dihydrochloride and Diclofenac Potassium in Pharmaceutical Preparations. Pharm Anal Acta 1:108.

26. Natesan S, Thanasekaran D, Krishnaswami V, Ponnusamy C (2011) Improved Rp- Hplc Method for the Simultaneous Estimation of Tranexamic Acid and Mefenamic Acid in Tablet Dosage Form. Pharm Anal Acta 2:115.

27. Subbaiah PR, Kumudhavalli MV, Saravanan C, Kumar M, Chandira RM (2010) Method Development and Validation for estimation of Moxifloxacin $\mathrm{HCl}$ in tablet dosage form by RP-HPLC method. Pharm Anal Acta 1:109.

28. Dharmender R, Madhavi T, Reena A, Sheetal A (2010) Simultaneous Quantification of Bergenin, (+)-Catechin, Gallicin and Gallic acid; and quantification of $\beta$-Sitosterol using HPTLC from Bergenia ciliata (Haw.) Sternb. Forma ligulata Yeo (Pasanbhe da). Pharm Anal Acta 1:104.

29. Sonawane LV, Bari SB (2010) Development and Validation of RP-HPLC Method for The Simultaneous Estimation of Amoxicillin Trihydrate and Bromhexine Hydrochloride from Oily Suspension. Pharm Anal Acta 1:107.

30. Prabu SL, Srinivasan M, Thiagarajan S, Marina Q (2010) Simultaneous Determination of Gatifloxacin and Ambroxol Hydrochloride in a Tablet Formulation by Liquid Chromatography. Pharm Anal Acta 1:110.

31. Lacassie E, Gaulier JM, Marquet P, Rabatel JF, Lachâtre G (2000) Methods for the determination of seven selective serotonin reuptake inhibitors and three active metabolites in human serum using high-performance liquid chromatography and gas chromatography. Journal of Chromatography B 742: 229-238a.

32. Tournel G, Houdret N, Hédouin V, Deveaux M, Gosset D, et al. (2001) High-performance liquid chromatographic method to screen and quantitate seven selective serotonin reuptake inhibitors in human serum. Journal of Chromatography B 761:147-158a.

33. Duverneuil C, de Grandmaison GL, de Mazancourt P, Alvarez JC (2003) A High- Performance Liquid Chromatography Method with Photodiode-Array UV Detection for Therapeutic Drug Monitoring of the Nontricyclic Antidepressan Drugs. Therapeutic Drug Monitoring 25: 565-573a.

34. Puozzo C, Filaquier C, Zorza G (2004) Determination of milnacipran, serotonin and noradrenaline reuptake inhibitor, in human plasma using liquid chromatography with spectrofluorimetric detection. Journal of Chromatography B 806: 221-228a.

35. Shinozuka T, Terada M, Tanaka E (2006) Solid- phase extraction and analysis of 20 antidepressant drugs in human plasma by LC/MS with SSI method. Forensic Science International 162: 108-112.

36. Labat L, Deveaux M, Dallet P, Dubost JP (2002) Separation of new antidepressants and their metabolites by micellar electrokinetic capillary chromatography. Journal of Chromatography B 773: 17-23.

37. Patti A, Pedotti S, Sanfilippo C (2007) Chiral HPLC analysis of milnacipran and its FMOC-derivative on cellulose-based stationary phases. Chirality 20: 63-68.

38. Choudhari VP, Nikalje AP (2010) Simultaneous Estimation of Atorvastatin Ezetimibe and Fenofibrate in Pharmaceutical Formulation by RP-LC-PDA Pharm Anal Acta 1:111.

39. Manassra A, Khamis M, el-Dakiky M, Abdel-Qader Z, Al-Rimawi F (2010) Simultaneous HPLC Analysis of Betamethasone and Clotrimazole in Cream Formulations. Pharm Anal Acta 1:113.

40. Zhang LJ, Yao YM, Sun JJ, Chen J, Jia XF, et al. (2010) An LC-MS/MS Method for Simultaneous Quantification of Seven Anti-HIV Medicines in Plasma of HIVinfected Patients. Pharm Anal Acta 1:102.

41. Rajender G, Narayana NGB (2010) Liquid Chromatography-tandem Mass Spectrometry Method for Determination of Paclitaxel in Human Plasma. Pharm Anal Acta 1:101.

42. Sharma HK, Jain N, Jain SK (2011) Development of Spectrophotometric Method for Quantitative Estimation of Amlodipine Besylate, Olmesartan Medoxomil and Hydrochlorthiazide in Tablet Dosage Form. Pharm Anal Acta $2: 126$

43. de Almeida VR, Brunetto AL, Schwartsmann G, Roesler R, Abujamra AL (2011) De-mystifying the Epigenetic Free for All: Pharmacophore Modeling for Epigenetic Cancer Therapy. Pharm Anal Acta 2:102e.

44. Jing W, Rui Z, Gui-yan Y, Rui-chen G (2011) Pharmacokinetics of Purified Paeonol and Paeonol in Moutan Cortex Decoction and Rhubarbmoutan Decoction. Pharm Anal Acta 2:124.

45. Mahapatra L, Sahoo GR, Panda MK, Parija S (2009) Pharmacokinetic Profile of Nimesulide in Bovine Calves. J Bioequiv Availab 1: 121-026.

46. Moreira RF, Rigato HM, Borges BC, Sverdloff CE, Oliveira RA, et al. (2009) Effect of Hyperlipemic Food on the Comparative Bioavailability of Two Bupropion Formulations after Administration of a Single Oral Dose of $150 \mathrm{mg}$ in Healthy Human Volunteers. J Bioequiv Availab 1: 103-111.

47. De Caro V, Giandalia G, Siragusa MG, Campisi G, Giannola LI (2009) Galantamine Delivery on Buccal Mucosa: Permeation Enhancement and Design of Matrix Tablets. J Bioequiv Availab 1: 127-134.

48. Zhu W, Masaki T, Cheung AK, Kern SE (2009) In-vitro Release of Rapamycin from a Thermosensitive Polymer for the Inhibition of Vascular Smooth Muscle Cell Proliferation. J Bioequiv Availab 1: 3-12.

49. Lima R, Vasconcelos T, Cerdeira R, Lefebvre M, Sicard E, et al. (2009) Bioequivalence of Final Tablet Formulation and Research Tablet Formulation of Eslicarbazepine Acetate in Healthy Volunteers. J Bioequiv Availab 1: 093098.

50. Bari SB, Bakshi AR, Jain PS, Surana SJ (2011) Application of UV Spectroscopy and First Order Derivative Method for Determination of Tamsulosin Hydrochloride in Bulk and Tablets. Pharm Anal Acta 2:120.

51. Konishi E, Takizawa Y (2010) Effect of Pre-Existing Immunity to Flaviviruses on Balanced Induction of Neutralizing Antibodies by a Denque Tetravalent DNA Vaccine in Mice. J Vaccines Vaccin 1: 102. 
Citation: Ravali R, Phaneendra M, Bhanu Jyothi K, Ramya Santhoshi L, Sushma K (2011) Recent Trends in Analytical Techniques for the Development of Pharmaceutical Drugs. J Bioanal Biomed S11. doi:10.4172/1948-593X.S11-002

52. Chen P, Atkinson R, Wolf WR. (2009) Single-laboratory validation of a highperformance liquid chromatographic-diode array detector-fluorescence detector/mass spectrometric method for simultaneous determination of watersoluble vitamins in multivitamin dietary tablets. J AOAC Int. 92:680-688.

53. Schellens JHM, Meeru JM, Bokke HWW, Rosing H, Tellingen O, et al. (1998) Cyclosporin A (CsA) strongly enhances oral Bioavailability of Paclitaxel (Pac) in cancer patients. Pro Am Soc Clin Oncol 17: 717a.

54. Sharma A, Conway WD, Staudinger RM (1994) Reverse-phase highperformance liquid chromatographic determination of taxol in mouse plasma. J Chromatogr 655: 315-319.

55. Arjanova OV, Prihoda ND, Yurchenko LV, Sokolenko NI, Frolov VM, et al (2010) Phase 2 Trial V-5 Immunitor (V5) in Patients with Chronic Hepatitis- C Co-infected with HIV and Mycobacterium tuberculosis. J Vaccines Vaccin 1: 103.

56. Nannan Panday VR, Meerum Terwot JM, Ten Bokkel Huinink WW (1998) The role of pro drug therapy in the treatment of cancer. Proc Am Soc Clin Oncol 17: $742 \mathrm{a}$.

57. Tzanavaras PD (2011) Automated Flow Injection Techniques in Pharmaceutical Analysis: A Useful tool. Pharm Anal Acta 2:130.
58. Hauck WW, Anderson S (1992) Types of bioequivalence and related statistical considerations.Int J Clin Pharmacol Ther Toxicol 30:181-187.

59. Khandave SS, Joshi SS, Sawant SV, Onkar SV (2010) Evaluation of Bioequivalence and Cardio-Hepatic Safety of a Single Dose of Fixed Dose Combination of Artemether and Lumefantrine. J Bioequiv Availab 2: 081-085.

60. Teksin ZS, Agabeyoglu I, Yamac K (2009) Bioavailability of PentoxifyllineChitosan Oral Matrix Tablet in Healthy Subjects. J Bioequiv Availab 1: 115-120.

61. Mahapatra L, Sahoo GR, Panda MK, Parija S (2009) Pharmacokinetic Profile of Nimesulide in Bovine Calves. J Bioequiv Availab 1: 121-026.

62. Moreno RA, Sverdloff CE, Oliveira RA, Oliveira SE, Borges DC, et al. (2009) Comparative bioavailability and pharmacodynamic aspects of cyclobenzaprine and caffeine in healthy subjects and the effect on drowsiness intensity. J Bioequiv Availab 1: 086-092.

63. Najib NB, Salem I, Hasan R, Idkaidek NM (2009) Effect of Truncated AUC Method on Drug Bioequivalence in Humans. J Bioequiv Availab 1: 112-114.

64. Shah D, Nandakumar S, Jaishankar GB, Chilakala S, Wang K, et al. (2011) PreTerm Exposure Patterns in Neonatal Intensive Care Unit Alters Immunological Outcome in Neonates. J Aller Ther 2:106. 